Available online at GSC Online Press Directory

GSC Biological and Pharmaceutical Sciences

e-ISSN: 2581-3250, CODEN (USA): GBPSC2

Journal homepage: https://www.gsconlinepress.com/journals/gscbps

(RESEARCH ARTICLE)

\title{
Prevalence of gynecological and obstetric disorders in patients associated with thyroid dysfunction
}

\author{
Ananya and P Kishore* \\ Department of Pharmacy Practice, Care College of Pharmacy, Oglapur (v), Damera (m), Warangal (rural), Telangana, \\ India - 506006.
}

Publication history: Received on 27 December 2019; revised on 06 January 2020; accepted on 09 January 2020

Article DOI: https://doi.org/10.30574/gscbps.2020.10.1.0252

\begin{abstract}
Thyroid gland is the most vital endocrine gland which plays a major role in growth, development and metabolism of human body. Thyroid dysfunction is an important causative factor of gynecological and obstetric abnormalities. This is an observational study conducted at Obstetrics and Gynecology department of a private hospital in Warangal district. A total of 60 patients were recruited in the present study after satisfying all inclusion and exclusion criteria. Among 255 patients with gynecological complaints, 195 patients (76\%) were euthyroid, 59 patients (23\%) were hypothyroid and 1 patient $(01 \%)$ had hyperthyroidism. Among 60 patients with thyroid dysfunction, the most common menstrual disorder observed was oligomenorrhoea. Predominant gynecological disorders associated with thyroid dysfunction were PCOS and Fibroid uterus (51 \%). The most common obstetric conditions associated with thyroid disorders are Pregnancy Induced Hypertension (PIH), miscarriage and oligohydramnios all together accounting for $67 \%$. As thyroid disorders may accompany with alterations in menstrual and reproductive function of women, screening for thyroid dysfunction should be made an integral part of investigations and in the treatment of gynecological and obstetric disorders.
\end{abstract}

Keywords: Thyroid dysfunction; Gynecological disorders; Hypothyroidism; Menstrual abnormalities

\section{Introduction}

Thyroid hormones have a profound influence on menarche, pubertal growth- development, menstrual cycle, fertility, fetal development, postpartum period, reproductive years and postmenopausal years [1]. Women are more likely to develop thyroid dysfunction. In women, thyroid disorders can cause a broad spectrum of reproductive illness ranging from abnormal sexual development to infertility [2]. Thyroid dysfunction can affect fertility in various ways resulting in anovulatory cycles, luteal phase defect, high prolactin (PRL) levels and sex hormone imbalances. Therefore, normal thyroid function is necessary for cyclic menstruation, fertility and pregnancy [3]. Both hyper and hypothyroidism may result in menstrual aberrations and infertility, although the hormonal and other biochemical aberrations are not the same in these two disorders. Thyroid dysfunction influences both menstrual flow and fertility, likely through changes in sex hormone levels, gonadotropin release and possibly ovarian function [4]. Common disorders associated with thyroid dysfunction in women are irregular bleeding patterns, prenatal complications, diminished conception and premature menopause. Oligomenorrhea and polymenorrhea are common in women with hyperthyroidism whereas in women with hypothyroidism, menorrhagia, polymenorrhea and rarely amenorrhea are observed. Anovulation is common with thyroid dysfunction. Prenatal complications like miscarriage, Pregnancy Induced Hypertension (PIH), Gestational Diabetes Mellitus (GDM), stillbirth, prematurity and post natal complications such as congenital abnormalities, post natal depression and abnormal post-partum bleeding are usually seen in women with thyroid disorders [5]. Undiagnosed and untreated thyroid disease can be a cause for infertility and other gynecological

\footnotetext{
${ }^{*}$ Corresponding author

E-mail address: kpcopsaz@gmail.com
} 
disorders. These conditions have important medical, economical, and psychology implications in our society [6]. This current study was done to study the prevalence of gynecological and obstetric abnormalities in thyroid dysfunction.

\section{Material and methods}

This retrospective study was carried out in the obstetrics and gynecology department of a private hospital. 60 women who were clinically diagnosed with thyroid disorder in gynecology department were selected for the study. The study was carried out for a period of 2 months after obtaining approval from Institutional Ethics Committee. Patient data was obtained from case sheets and interaction with patients and care givers.

\subsection{Inclusion criteria}

Women with a history of thyroid disorder presenting with menstrual irregularities e.g., Menorrhagia, polymenorrhea, oligomenorrhea and hypo menorrhea.

Women diagnosed with thyroid disorders (Hypothyroidism, Hyperthyroidism) attending gynecology department.

\subsection{Exclusion criteria}

Women with euthyroid profile

\section{Results}

Among 255 patients with gynecological complaints, 195 patients (76\%) were euthyroid, 60 patients (23\%) were hypothyroid and 1 patient (01\%) with hyperthyroidism. Menstrual, gynecological and obstetric data was collected from 60 patients with abnormal thyroid function.

The predominant thyroid dysfunction is hypothyroidism affecting about $99 \%$ of women in the study. In this study, $45 \%$ were in the age group 21-25 years, $28 \%$ were between $26-30$ age group.

Table 1 Parity wise distribution

\begin{tabular}{ll}
\hline Parity & Percentage \\
\hline Nulliparous & 37 \\
$1^{\text {st }}$ parity & 35 \\
$2^{\text {nd }}$ parity & 25 \\
$3^{\text {rd }}$ parity & 01 \\
$4^{\text {th }}$ parity & 01 \\
\hline
\end{tabular}

Parity is defined as the number of times a female has given birth to a fetus with a gestational age of 24 weeks or more, regardless of whether the child was born alive or was stillborn. In the parity index, 22 of the cases (37\%) were nullipara followed by $1^{\text {st }}$ parity women of 21 cases (35\%).

Table 2 Pattern of bleeding in thyroid dysfunction

\begin{tabular}{ll}
\hline Pattern of bleeding & Percentage \\
\hline Cyclical & 27 \\
Oligomenorrhea & 35 \\
Menorrhagia & 25 \\
Dysmenorrhea & 07 \\
Polymenorrhea & 03 \\
Amenorrhea & 01 \\
Hypomenorrhea & 01 \\
\hline
\end{tabular}


Among the 60 patients, the most common menstrual disorder observed was oligomenorrhoea in 21 patients (35\%) followed by cyclic menstruation in 16 patients (27\%) and menorrhagia in 15 patients (25\%).

Table 3 Distribution of signs and symptoms of gynecological disorders in thyroid cases

\begin{tabular}{ll}
\hline Symptom & Percentage \\
\hline Abdominal pain & 38 \\
Excessive menstrual cycle & 22 \\
Irregular menstrual cycle & 23 \\
Anxious to conceive & 10 \\
Pedal edema & 8 \\
\hline
\end{tabular}

Abdominal pain and irregular menstrual cycle (38\% and $23 \%$ ) was the chief presenting complaints among study participants.

Table 4 Distribution of data based on duration of Thyroid dysfunction

\begin{tabular}{ll}
\hline Duration of dysfunction & Percentage \\
\hline < 5 months & 15 \\
< 1 year & 42 \\
2 years & 15 \\
3 years & 07 \\
4 years & 03 \\
$>$ 5 years & 10 \\
\hline
\end{tabular}

Of 60 patients, 25 patients (42\%) had a history of thyroid dysfunction since 1 year.

Of 60 patients, 41 cases (68\%) were diagnosed with gynecological disorders and 20 of the total cases (32\%) were diagnosed with obstetric disorders.

Table 5 Distribution of data based on associated gynecological disorders

\begin{tabular}{ll}
\hline Diagnosis & Percentage \\
\hline PCOS (Polycystic Ovarian Syndrome) & 29 \\
Fibroid uterus & 22 \\
Infertility & 20 \\
AUB (Abnormal Uterine Bleeding) & 9 \\
Fibro adenoma of breast & 9 \\
Endometriosis & 2 \\
Ovarian cyst & 9 \\
\hline
\end{tabular}

The most common gynecological conditions associated with thyroid disorders are PCOS and Fibroid uterus both accounting for $51 \%$. 
Table 6 Distribution of data based on obstetric disorders

\begin{tabular}{ll}
\hline Diagnosis & Percentage \\
\hline Miscarriage & 19 \\
Oligohydramnios & 19 \\
Latent labour & 14 \\
PIH & 29 \\
GDM & 14 \\
Eclampsia & 5 \\
\hline
\end{tabular}

The most common obstetric conditions associated with thyroid disorders are PIH, miscarriage and oligohydramnios all together accounting for $67 \%$.

\section{Discussion}

In patients with gynecological disorders most of them had thyroid dysfunction. The prevalence of hypothyroidism was high (99\%) in our study than hyperthyroidism. Bhattacharjee S et al., reported a prevalence of $72.5 \%$ of hypothyroidism among all cases of thyroid disorders [7]. This is in acceptance of the fact that hypothyroidism remains the leading thyroid disease.

In this study, $73 \%$ of thyroid disorders were between 21-30 years of age which is similar to a study conducted by Ramya MR et al., 93.8\% of hypothyroid cases were between 21-40 years of age [8]. Thyroid disease is the most common endocrine condition affecting women of reproductive age. Importantly subclinical disturbances are more frequent in women.

In the present study, majority of patients were nulliparous (37\%), followed by $1^{\text {st }}$ parity women (35 \%).This is comparable with Kumar AHS et al., (43\%) (2). This might be due to impairment in ovulation. Abnormality of thyroid hormones can interfere with cyclic ovulation.

Most common menstrual irregularity found in our study was oligomenorrhea, which was seen in $35 \%$ of patients which is contrast to a study conducted by Ramya MR et al., where most of them had Menorrhagia (72.5\%) [8]. Thyroid dysfunction may fluctuate the levels of Thyroid Releasing Hormone (TRH) and prolactin levels contributing to menstrual abnormalities. The likely mechanism of menstrual disturbances is due to an increased sensitivity to gonadotropin releasing hormone, resulting in a raised level of luteinizing hormone and sex hormone binding globulin, causing a rise in estrogen levels.

The most common gynecological complaints are abdominal pain and acyclical menstrual cycle (excessive menstrual flow, irregular menstruation). In the study of Bhattacharjee $S$ et al., menstrual disorders are the common symptoms (21.5\%) [7].

Predominant gynecological disorders associated with thyroid dysfunction are PCOS, Fibroid uterus (51 \%) which is contrast to a study conducted by Bhattacharjee $S$ et al., the most common gynecological conditions associated with thyroid disorders are AUB and infertility both accounting for 5.83\% [7]. In the presence of thyroid disorders, ovarian morphology becomes polycystic. Underlying pathophysiology includes rise in levels of TRH, TSH, Prolactin and dehydroepiandrosterone.

Predominant obstetric complications are PIH, miscarriage and oligohydramnios which is similar to the study conducted by where Taylor PN et al., TSH (Thyroid Stimulating Hormone) $>4.5 \mathrm{mU} / \mathrm{L}$ is associated with increased risk of miscarriage [9]. Poor control of thyroid disorder during pregnancy may increase the risk of adverse pregnancy outcomes and a reason for cesarean delivery. 


\section{Conclusion}

Hypothyroidism is more common than hyperthyroidism. The study revealed that women in the age group of 21 to 30 years are more prone to thyroid disorders. Thyroid dysfunction should be considered as an important associated factor for gynecological abnormalities. From this study, it may be concluded that there is a strong correlation of thyroid dysfunction and menstrual disorders. Correction of thyroid abnormalities also relieves gynecological and obstetric complications. This will avoid unnecessary hormonal treatment and surgical procedures. With routine monitoring and proper treatment, patients with thyroid disorders can lead healthy life with no systemic complications. Clinical pharmacist should educate patient regarding routine health checkups and medication adherence.

\section{Compliance with ethical standards}

\section{Acknowledgments}

I thank Dr. Anjani devi, Department of gynecology and obstetrics, Dr. Kishore, Department of pharmacy practice and my dear friends for their support towards the successful completion of this work.

\section{Disclosure of conflict of interest}

There are no conflicts of interest to declare by any of the authors of this study.

\section{References}

[1] Nangia SA and Vinita S. (2016). Role of Thyroid Dysfunction in patients with Menstrual Disorders in Tertiary Care Center of Walled City of Delhi. The Journal of Obstetrics and Gynaecology of India, 66(2), 115-119.

[2] Ashok KHS and Saravanan S. (2017). A study of prevalence of thyroid disorders in patients with abnormal uterine bleeding. International Journal of Reproduction, Contraception, Obstetrics and Gynecology, 6(3), 1036-1039.

[3] Ngozi CO and Ehimen PO. (2019). Evaluation of thyroid function in infertile female patients in port harcourt, Nigeria. Tropical Journal of Obstetrics and Gynaecology.

[4] Madhu D, Ravinder K and Dinesh K. (2107). Thyroid profile in women with menstrual disorders. International Journal of Reproduction, Contraception, Obstetrics and Gynecology, 6(8), 3300-3305.

[5] Demetrios A and Koutras. (2006). Disturbances of Menstruation in Thyroid Disease. Annals of the New York Academy of Sciences, 816(1).

[6] Indu V, Renuka S, Sunil J and Satinder K. (2012). Prevalence of hypothyroidism in infertile women and evaluation of response of treatment for hypothyroidism on infertility. International Journal of Applied and Basic Medical Research, 2(1).

[7] Somen B, Yogendra J, Shiv SS and Arti P. (2016). A study of thyroid disorders in females attending obstetrics and gynecology outpatient department of a tertiary care institute of central India. International Journal of Research in Medical Sciences, 4(5), 1320-1324.

[8] Ramya MR, Parvathavarthini, DarshanS and RSankareswari. (2017). Menstrual disorders associated with thyroid dysfunction. International Journal of Reproduction, Contraception, Obstetrics and Gynecology, 6(11), 5113-5117.

[9] Taylor PN. (2014). TSH levels and risk of miscarriage in women on long term levothyroxine: a community-based study. J ClinEndocrinolMetab, 99(10), 3895-3902.

\section{How to cite this article}

Ananya and P Kishore. (2020). Prevalence of gynecological and obstetric disorders in patients associated with thyroid dysfunction. GSC Biological and Pharmaceutical Sciences, 10(1), 13-17. 